\title{
Healthcare expenditure and income generation: a US case
}

\section{Claudio Socci ${ }^{\star}$, Maurizio Ciaschini, Rosita Pretaroli and Francesca Severini}

\author{
Department of Economics and Law, \\ University of Macerata, \\ Via Crescimbeni 14, 62100 Macerata, Italy \\ Email: claudio.socci@unimc.it \\ Email: maurizio.ciaschini@unimc.it \\ Email: rosita.pretaroli@unimc.it \\ Email: francesca.severini@unimc.it \\ *Corresponding author
}

\begin{abstract}
As well as a policy variable that has the potential to affect economic growth, a reform of healthcare expenditure involves the change of GDP because of its role played inside the processes of generation and distribution of income. In this paper, an effort is made to verify, through the macro multipliers approach, the possibility to design a convenient policy for healthcare expenditure. Such a policy permits to rule the incidence of health's expenditure with respect to total output and without neglecting the effects that it originates on the main macroeconomic variables like as GDP. The empirical analysis is built on an social accounting matrix (SAM) framework developed for the USA socio-economic system. The convenient policy differs from selective policy for health sector. The first one implies a complex redistribution of the resources in order to achieve the best result in terms of reduction of the ratio between health expenditure and GDP but without depressing total industrial output and income generation.
\end{abstract}

Keywords: healthcare expenditure; MM approach; social accounting matrix; SAM; multi-sectoral extended model.

Reference to this paper should be made as follows: Socci, C., Ciaschini, M., Pretaroli, R. and Severini, F. (2019) 'Healthcare expenditure and income generation: a US case', Int. J. Healthcare Policy, Vol. 1, No. 1, pp.24-51.

Biographical notes: Claudio Socci is a Professor of Economic Policy at the Department of Economics and Law, University of Macerata. He was promoted to Full Professor and Associate Professor. He received his $\mathrm{PhD}$ and Master of Science in Economics at the University of Ancona. His research interests relate prevalently with input-output analysis, social accounting matrix and empirical application for income distribution, tax reforms, water, ICT, wine, environmental and health. He is a co-editor of Enometrica. He is a member of the International Association of Input-Output Technique, the International Association of ALASS and the Italian Society of Public Economics.

Maurizio Ciaschini is a Full Professor of Economic Policy at the Department of Economics and Law, University of Macerata. He was the Dean of the Faculty of Communication Science and of the Department of Economic Development Studies at University of Macerata. He is the Chief Editor of Enometrica. His research interests relate prevalently with input-output analysis, nonlinear 
dynamics and theoretical and applied economics. As a NATO Senior Fellow, he has been invited at the Institute of Economic Analysis of NYU where he collaborated with the team of Prof. W. Leontief (Nobel price 1973).

Rosita Pretaroli is an Assistant Professor of Economic Policy at the Department of Economics and Law, University of Macerata. She teaches economy and communication, economic policy. She was promoted to Associate Professor. She received his $\mathrm{PhD}$ at the University of Ancona and Master of Science in Health Economics at the CORIPE. Her research interests relates prevalently with multi-sectoral analysis and empirical application for health output, income distribution, tax reforms for environmental policy, wine sector. She is co-editor of Enometrica, the international review of European Association of Wine Economists. She is a member of International Association of Input-Output Technique.

Francesca Severini is Junior Researcher of Economic Policy at the University of Macerata where she teaches economic policy. She received her $\mathrm{PhD}$ in Economics at the University of Polytechnics of Marche in March 2009. She received her Master in Economics at the University of Polytechnics of Marche. She participated to the research project 'SAM for Syria' financed by FAO under the coordination of the Catholic University. She collaborated with the ISMEA in developing the CGE model for the analysis of the European policy on agriculture. Her research interests focus mainly on the computable general equilibrium analysis and its empirical application to investigate the effects within the economic system of environmental policies, fiscal federalism reforms, wine and health output oriented policies.

This paper is a revised and expanded version of a paper entitled 'Convenient policy for health care expenditure in a multisectoral extended model' presented at the 19th International Input-Output Conference, Alelxandria, Virginia, USA (in metropolitan Washington, DC), 13-17 June 2011.

\section{Introduction}

Debate on US health policy focuses on limiting the growth of health spending that is now around $18 \%$ of GDP and its public share accounts for almost half of the total ${ }^{1}$. In this debate, many of the important questions related to rising health expenses involve the institutional arrangements that preside over its financing and often empirical researches give advice on how to depress public demand for healthcare. Nevertheless the attempt to develop an understanding on better public policies that have to be able either to ensure society's efficient consumption of health and prevent increasing expenditures should take into account the driving force of healthcare services in determining the total output of US economy.

Rising healthcare spending is a topic of absolutely general concern also emerged after the passage of the 'affordable care act', but unlike the past, increasingly literature focuses on the positive relation between health demand, income growth and better health interventions (Hall and Jones, 2007; Al-Issis and Miller, 2013; Busse, 2002). This viewpoint considers the health sector as a leading activity whose expenditure has the potential to pull forward a wide array of other industries including the traditional sector of manufacturing, education, financial services, communications and construction ${ }^{2}$. This 
suggests a fundamental repositioning of the debate about healthcare from how governments can limit spending to how to obtain economic positive direct and indirect effects from health spending that is undertaken.

The US health system has more than a few peculiarities. They are directly consequences of a series of incremental reforms not always inspired by public authorities. These modifications affected, from time to time, partial aspects of the healthcare system improving contradictions. The US healthcare system is considered a very expensive system showing the higher fraction of GDP devoted to healthcare services. Several international reports assign to US health system the worst performance in health between industrialised countries. Nevertheless, it is undoubtedly the most advanced system in the field of biomedical research and innovation. It is probably because of its paradoxes that it is often considered a 'non-system', especially for the lack of a central national strategy concerning the approach to financing. However, the size and the scope of the recently passed 'patient protection and affordable care act' demonstrates the economic importance of healthcare spending in US economy and perhaps a new thought on this direction. There is no doubt that health expenditures are able to stimulate, as for the public and the private share, an articulated production process where various types of market and non-market inputs are consumed. While many questions were raised by economists around the issue of rising costs of US healthcare system and its financing method, none study conducted a preliminary analysis about the role of healthcare in the income generation (Fogel, 2009).

This paper offers a first look at this large question by focusing and further developing the issue of economic relevance related to US health product inside the processes of generation, distribution and redistribution of national income. The effort is made in order to evaluate the potential economic impact of health among all component of total output in a multi-sectoral framework (Ciaschini et al., 2011). The new perspective of researches on healthcare services that this paper aims to enhance should be founded on the quantification of the relative force of the health sector in driving total output. Rather than being considered erroneously an indefinitely 'squeezable' sector of public expenditure the economic analysis can gains insights into the economic consequences of health sector and its role into public policy design ${ }^{3}$.

We develops the macro multipliers (MMs) analysis in order to study the macroeconomic relevance of health product either as a policy variable or as a policy target (Ciaschini et al., 2011). This type of methodology allows to verify the prominence of health output inside the key policy structures that are underlie by the circular flow of income that inspires the SAM scheme (Ciaschini and Socci, 2007a, 2007b). All key policy structures, as for policy variable and for policy target, are revealed by the decomposition of the reduced form of the multi-sectoral extended model that is implemented on the US social accounting matrix (SAM), which describes all phases of income generation. Of particular importance is the analysis developed on the reduced form of the model that is suitable for policy simulation with the innovative approach of MM (Ciaschini et al., 2009).

In particular the analysis of MM focuses on the inner composition, or key-structures, determined by the structural matrix, of the policy control (exogenous final demand) and of the policy objective (total output), as the compositions that rule the magnitude of the policy effect. The relevance of health within these key structures reveals the weight of 
health product as value-added generator and as total-output stimulator with respect to all other outputs. Income generation, technologic and labour-force stimulus are, in fact, the threefold features in designing a policy of reform ${ }^{4}$. Once determined all key structures are scheduled according the value of the key index for the health product, the health-key-index. In this respect we are able to compare the relevance of the US health product both in terms of policy variable and policy object.

For this purpose, the second section of this paper describes some characteristics of the institutional framework of US healthcare system. The third section shows the multi-sectoral extended model and the SAM framework. The fourth section shows the results of the traditional dispersion analysis performed on the structural matrix. The fifth section describes the MMs approach and the health-key-indices of key structures that the decomposition reveals. The last section presents the major results stressing the role played by the US health product as an economic policy variable.

\section{Heath care services in US SAM}

The basic organisation of the database is inspired by the SAM scheme and follows the matrix presentation of national T-accounts (UN, 1993). The income circular flow is quantified and connects data on the production process (final demand, total output and value added generation) gathered by activities which play the role of industries, with data on the distribution process (factor allocation of value added, primary and secondary distribution of incomes) collected by institutional sectors.

The production and the demand for healthcare services are included into the circular flow of income as all the other types of commodities. Highlighting the healthcare services therefore requires the construction of a database that integrates health sector with production and income accounting. The SAM is the accounting scheme that properly provide this integration. This instrument is able to identify all flows related to healthcare services within the production and to detect the ability both to generate value added and to distribute income. It finally registers the relevance of healthcare production in final demand.

The SAM for the USA, year 2009 and at current price ${ }^{5}$, is obtained through the link between the I-O table and the national accounts by institutional sectors (BEA, 2009).

The matrix can be broken up into quadrants which can be further divided into blocks. A brief sketch of blocks in each of the six sub matrices, as shown in Table 1, can be easily described as follows:

- quadrant 1 - production and final demand formation

- quadrant 2 - primary allocation of income

- quadrant 3 - secondary distribution of income and capital formation

- quadrant 4 - economic transaction with the rest of the world.

Accounts are organised in rows and columns corresponding to eight headings: output, compensation of employees, other incomes, households, business, capital formation, government and rest of the world. 
Table 1 SAM for the USA economy, year 2009 (million of dollars)

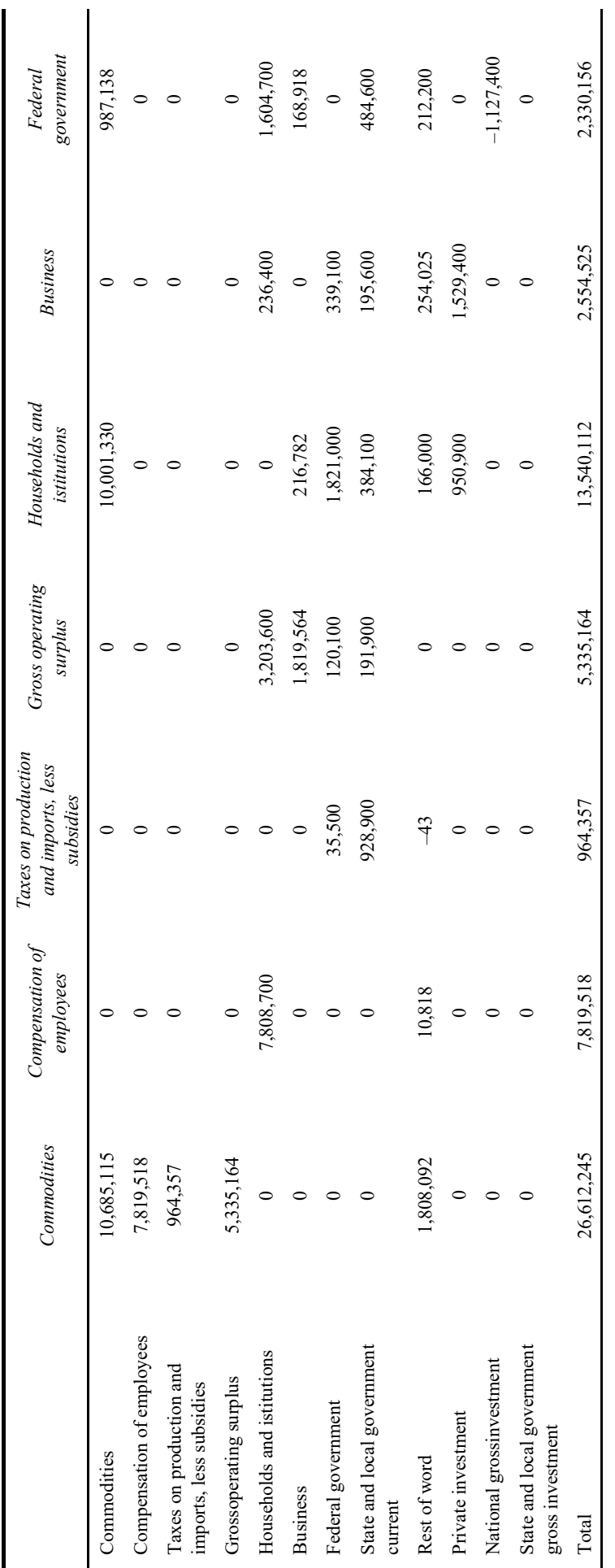


Healthcare expenditure and income generation

Table 1 SAM for the USA economy, year 2009 (million of dollars) (continued)

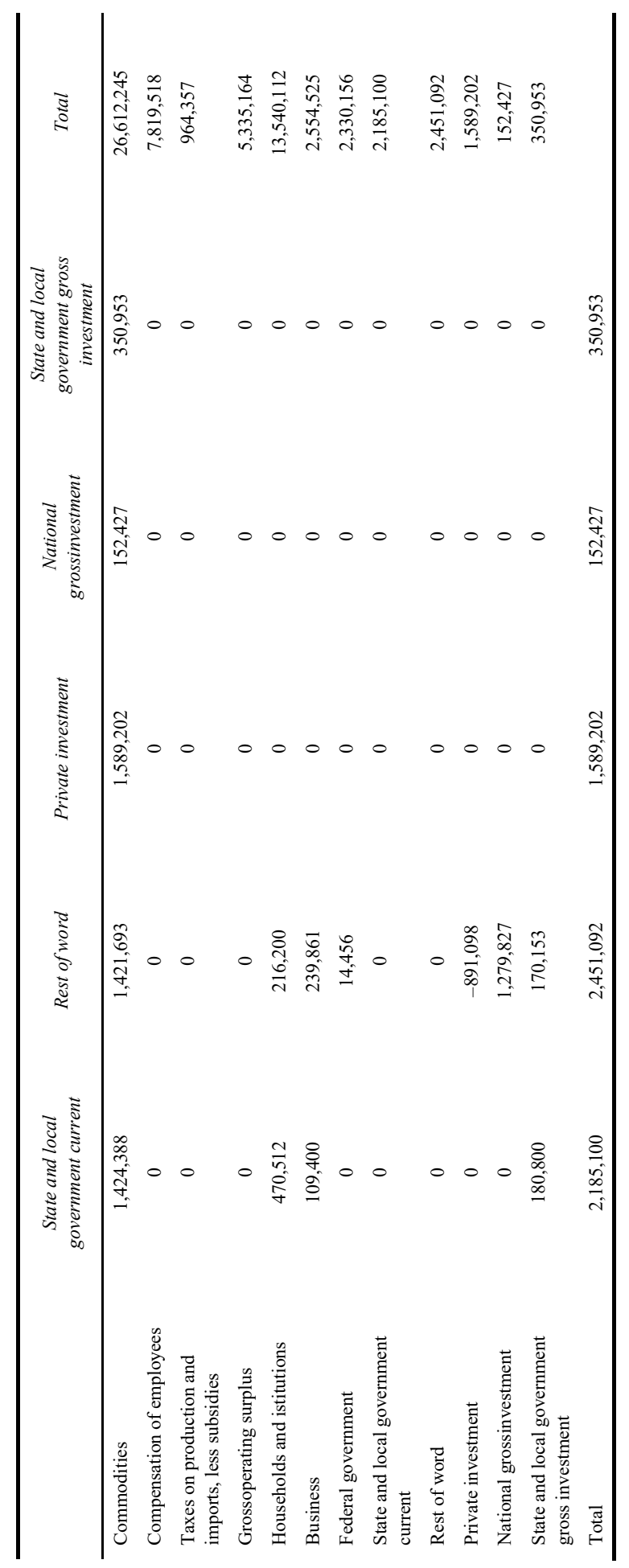


Each quadrant in Table 1, then, gives account of the national flows and their allocation in different blocks in order to describe the whole circular flow. Table 1 gathers data from 67 input-output sectors, five institutional sectors ${ }^{6}$, three value added components (compensation of employees, taxes on production and imports, less subsidies, gross operating surplus), last quadrants (5 and 6) describe flows between regions and the public administration and the rest of the world.

Inside the phases of generation, distribution and redistribution of income that the SAM for the US economy describes, healthcare services can be twice identified. First the healthcare services derive from the final consumption programmed by households and others institutional sectors.

This part of private healthcare output can be generated by two type of activities: ambulatory healthcare services (54) and hospitals and nursing and residential care facilities (55). The amounts are respectively 823,703 and 889,594 million of dollars. The remaining part is qualified as federal government production (884,400 million of dollars) and state and local government (431,200 million of dollars). In particular the final consumption by households respectively is for the ambulatory healthcare services 783,734 million of dollars and is for the hospitals and nursing and residential care facilities 884,167 million of dollars.

The part of these healthcare services output, not destined to the final demand, represents the intermediate consumption by all other commodities of ambulatory healthcare services (39,967 million of dollars) and Hospitals and nursing and residential care facilities (5,178 million of dollars).

The difference between the total output of healthcare services and the intermediate consumption by the other production processes represents the final demand that includes exports (252 million of dollars).

\section{Extended multi-sectoral model framework}

In our analysis we will use a multi-industry, multi-factor and multi-sector model following a Miyazawa approach (Miyazawa, 1976; Miller and Blair, 2010; Bulmer-Thomas, 1982), but in our case using extended income circular flow based on SAM scheme (Ciaschini and Socci, 2007b). For the extended income-output model we adopt fixed prices and constant technical coefficients and shares. In fact, the results attained in social accounting encourage the attempt to build an extended version of the income circular flow where the interactions between industries and institutions could be specified and evaluated.

Figure 1 shows a diagram where the fundamental mechanism of production and distribution is shown in terms of interaction among industries, institutional sectors and primary factors (value added components). In Figure 1 each arrow identifies an expenditure flow while each box a matrix transformation of a flow variable into another. In the upper part of the figure, the inter industry demand loop in Figure 1 can be recognised. The extended income-output loop emerging in Figure 1 allows for an extension of the study of the propagation. We can choose, in fact, on which flow variable to act with a unit shock and on which variable to observe the effects. For each flow variable we need to specify an order of magnitude, such as the scale and a composition, or the structure. If we want to impose a unit shock on final demand and observe its propagation on domestic output we need to refer to the equation of the reduced form of 
the model, but other arrangements of structural matrices are easily found if we need to impose a shock on income redistribution and observe it on value added by factor.

Figure 1 Extended income-output model (see online version for colours)

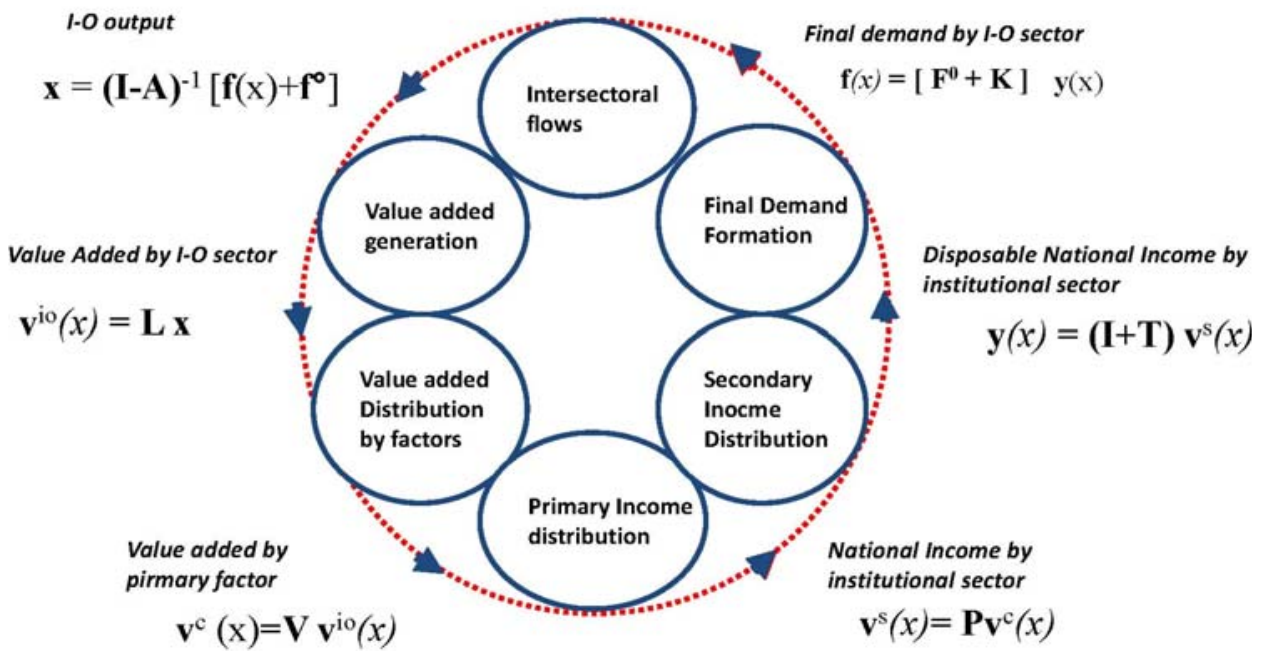

As shown in Figure 1, with the dotted arrow, the income distribution process creates a feedback loop between industry output and final demand. This loop is built through various logical phases (UN, 1993). The production process, that takes place at industry level, generates total output, $x$ and gross value added by the $n$ I-O industries $v(x)$, (gross value added generation). Value added by I-O industry is then allocated to the $c$ value added components (primary factors), $v^{c}(x)$ (gross value added allocation). Value added by components is then allocated to the $s$ institutional sub-sectors, $v^{s}(x)$ (primary distribution of income). Value added by institutional sectors is then redistributed among them through taxation and transfers to generate disposable incomes by the $s$ institutional sub-sectors, $y(x)$ (secondary distribution of income). Finally disposable income will generate final demand by institutional sub-sectors which will be transformed into final demand by I-O industries, $f(x)$ (final demand formation).

\section{Dispersion analysis for healthcare services}

The reduced form of the model has the potential to underline the direct and indirect effects on the disaggregated output generated. This is possible performing an exogenous shock through a predetermined final demand or through the change of any other macroeconomic variables described in the model.

Starting from the reduced form we can build two types of indexes of dispersion that are able to point out the role of any products in terms of sensitivity and power dispersion. The first type of index can appreciate the relevance of a good to activate the production chain or, to put it better, the index evaluates an increase of a unit final demand shock of the $i^{\text {th }}$ good in terms of a change of the output of the other commodities. The second type of index evaluates the relevance of a good when a unit final demand shock of all commodities is performed. 
The matrix $\mathrm{R}$ allows to build the indexes of dispersion focusing on the commodity ambulatory healthcare services and hospitals and nursing and residential care facilities in order to determine their role as key commodities. Once the Rasmussen dispersion indexes (Rasmussen, 1956) are determined, it is possible to give a rank of all goods in terms of power and sensitivity of dispersion.

Figure 2 Backward dispersion: healthcare services relevance (see online version for colours)

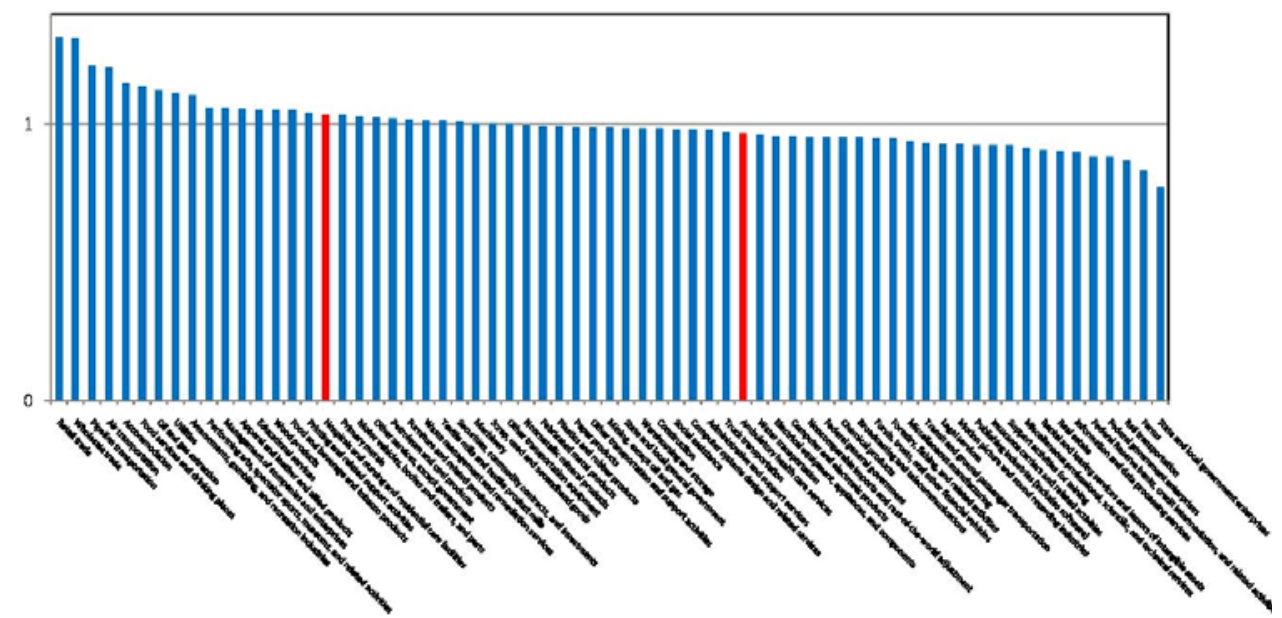

As in Figure 2 the two typologies of private healthcare services are differently ranked. Hospitals and nursing and residential care facilities has a backward index equal to 1.03 . It is ranked at the 17th position while ambulatory healthcare services index is equal to 0.97 (42nd position).

Figure 3 Forward dispersion: healthcare services relevance (see online version for colours)

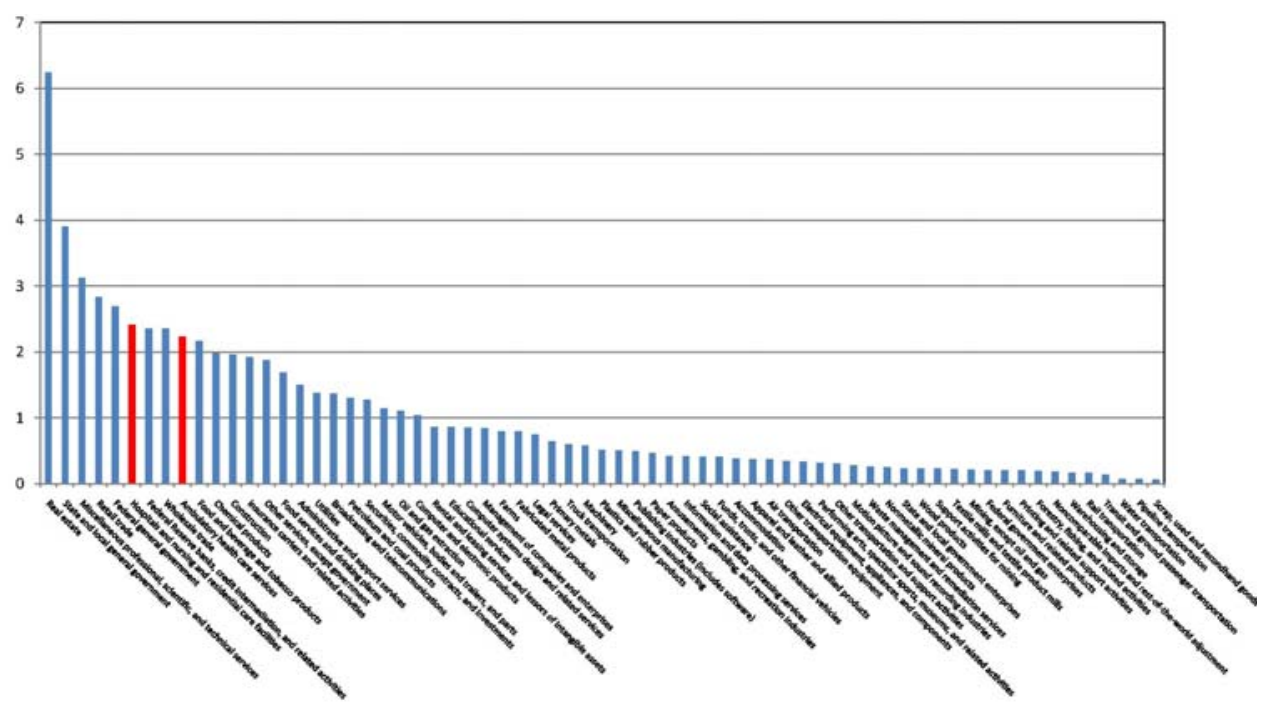


The analysis then shows that hospitals and nursing and residential care facilities plays a significant role in activating other production processes. Consequently, the income generation is higher than the other type of healthcare commodity. Moreover, the commodity hospitals and nursing and residential care facilities is placed in the first positions with respect to all the other commodities in the SAM.

Figure 3 shows the sensitivity index. In this case, both commodities are ranked in top positions: hospitals and nursing and residential care facilities is the sixth (2.41) while Ambulatory healthcare services is the ninth (2.23). In this case, the index reveals the role of the commodity within the income circular flow in terms of final demand formation. Indeed the index shows the importance of healthcare commodity not in terms of direct impact on other productions but in terms of indirect contribution to the final demand formation. This can be attributed to the ability of this commodity in value added income generation and thus in final demand formation.

\section{Healthcare services and MM approach}

The direct and indirect effects of final demand changes on total output are then quantified in our multi-sectoral extended model from structural matrix ${ }^{7}$. In extended multi-sector model, 'healthcare services' are considered as a typical commodity contributing through the production process to the generation and allocation of value added, to determine the endogenous final demand. Within the political debate, a normative analysis of health services becomes crucial. The production of health services indeed, may represent a target to be reached or, in alternative, a tool for the control of other typologies of production. The role of health services production can be recognised through the MMs approach. This approach allows bringing out the policies that the system considers being optimal or convenient to the economic policy objective, using the mathematical tool of the singular value decomposition (Lancaster and Tiesmenetsky, 1985) ${ }^{8}$.

Hence, this structural matrix of the model can be easily decomposed in three different matrices:

$$
R=Z M P
$$

In our original $[n, n]$ extended model, we can say that, given our matrix $R$, we are able to isolate impacts of different (aggregate) magnitude, since that MM are embodied in matrix $R, m_{i}$ can be activated through a shock along the demand structure $p_{i}$ and its impact can be observed along the output structure $z_{i}$.

When final demand vector crosses a structure in $P$, the vector of total output crosses the corresponding structure in $Z$ and the ratio between the moduli of the two vectors gives the corresponding scalar $m$. Singular values $m_{i}$, then, determine the aggregated effect of a final demand shock on output. For this reason, we will call them MMs. The MM are aggregated, in the sense that each of them applies on all components of each macroeconomic variable taken into consideration and are consistent with the multi-industry specification of the model. 


\section{The healthcare services as policy objective and policy control}

In developed countries, especially in US, the healthcare system is affording a significant makeover in terms of sustainability, social desirability and profitability in economic/employment terms. The economic sustainability of healthcare services is closely related to the amount of people to be cared ${ }^{9}$ and the system for sharing the expenditure for the services provided according to the welfare state.

When the economy is characterised by low growth rates, the economic and financial sustainability of public expenditure, along with other social and demographic variables such as changes in composition and growth of the population, contributes to the desirability of certain types of healthcare systems. This can be the case of the US economy where the healthcare system can represent a key sector in terms of stimulating total output and employment.

The characteristics of the demand for healthcare services is comparable to those commodities with low elasticity and allows to analyse the role of the healthcare system likewise all the other market and non-market goods. Following this idea, given that the importance of a specific production in the economy can be analysed in terms of income and employment generation, the healthcare services production can be seen as an economic policy instrument and/or objective. This approach allows overcoming the criticisms that generally emerge on the desirability of public or private healthcare expenditure and of universal coverage of the population.

If the production of healthcare services represents a key production for the economy, then its economic and social desirability becomes a support to its production ${ }^{10}$. In other words, both the concern on the desirability of non-market healthcare services and its strong and rigid demand, force to point the attention on economic models able to treat the healthcare system and analyse its role as an economic policy instrument and objective.

For this purpose, the multi-sector and MM approaches allow verifying the relevance of healthcare services and the structures related to their production when they assume the role of policy target or policy control to achieve socio-economic objectives such as income generation, employment and income redistribution to support the poorer segment of the population. The MM approach is able to identify all the possible structures related to the target variable and the control variable that the policy maker can use. When the purpose of the research is identifying the policies that consider as an objective or as a control variable one of the several health services included in the SAM, the set of structures to be considered is selected by calculating an index on the set of key structures that emerges from the decomposition.

The set of key structures (both for objective variable and control variable) is easily rearranged according the constant absolute change.

This phase is needed in order to build two type of index through which each structure can be measured. In particular, these indexes can be calculated on each singular commodity, for example healthcare services and are able to reveal its relative role among all key structures and quantify its importance both in terms of objective variable and control variable.

As it is for the key objective structures, given matrix $Z$, it is possible to define the index: 


$$
\mu_{i j}=\frac{\left|m_{i} z_{i j}\right|}{\frac{1}{n}\left|m_{i} z_{. j}\right| / \frac{1}{n^{2}} \sum_{j=1}^{n}\left|m_{i} z \cdot j\right|}
$$

It quantifies the importance of $i^{\text {th }}$ commodity in all $n$ key objective structures. In particular, the index can reveal the importance of the selected commodity inside the key objective structures $\left(z_{i}\right)$ when the correspondent MMs $\left(m_{i}\right)$ and the associated policy structure $\left(p_{i}\right)$ are activated ${ }^{11}$.

As for the key control structures, it is possible to define the index starting from matrix P:

$$
\gamma_{i j}=\frac{\left|p_{i j}\right|}{\frac{1}{n}\left|p_{. j}\right| / \frac{1}{n^{2}} \sum_{j=1}^{n}\left|p_{. j}\right|}
$$

The index quantifies the importance of the $i^{\text {th }}$ commodity in all $n$ key control structures. In particular, the index can reveal the role played by the selected commodity inside the key control structures $\left(p_{i}\right)$.

In this case, the index highlights the importance of the commodity within the structures related to the policy instruments. These structures will activate a predetermined MM that will be associated to a given vector of the target variable composition.

The indexes then allow bringing out the role of the selected commodity. When the commodity is the policy target, we concentrate on the policies that ensure the maximum effect on the selected commodity. In other words, the structures that are favourable to the $i^{\text {th }}$ commodity are identified, similarly to the backward concept. Differently, when the commodity is used as a policy instrument, we concentrate on the structures that mostly require this production. Then we identify the ability of the commodity to contribute to the production of all other commodities, similarly to the forward concept.

\subsection{The key-objective-structures index}

The importance of healthcare output, detected with reference to the economic policy design, is quantified among the structures revealed by the MM approach. All indexes described in the previous section stress the relevance of private health. They allow quantifying how important is private healthcare output in influencing output change when an exogenous shock affects final demand components.

If the economic policy will develop through the objected represented by the disaggregated output for the US economy it is necessary to verify the weight of ambulatory healthcare services (commodity 54) and hospitals and nursing and residential care facilities (commodity 55) inside the composition of the key objective variable. We therefore assume that the policy maker objective is the healthcare output. Given the economic structure of US economy described by the SAM, through the MM approach we are able to select the structures of the vector of policy targets that are favourable to the production of both healthcare goods. If the policy maker aims to 
achieve specific quantitative effects in healthcare output, he must use these structures that are endogenously predetermined by the economic institutional structure.

Several structural differences can be stressed considering the value of the key-objective-structures index following the equation (2) with respect to good ambulatory healthcare services and hospitals and nursing and residential care facilities.

The results regarding the key-objective-structures index for the US instance are shown in Table 2.

Table 2 The value index of key policy for the objective variable: $\mu_{54, j}$ (ambulatory healthcare services) and $\mu_{55, j}$ (hospitals and nursing and residential care facilities)

\begin{tabular}{|c|c|c|c|c|c|}
\hline $\begin{array}{l}\text { Index key } \\
\text { structures } \\
\left(\mu_{., j}\right)\end{array}$ & $\begin{array}{c}\text { Ambulatory } \\
\text { healthcare } \\
\text { services } \\
\text { (commodity 54) }\end{array}$ & $\begin{array}{l}\text { Hospitals and } \\
\text { nursing and } \\
\text { residential } \\
\text { (commodity 55) }\end{array}$ & $\begin{array}{c}\text { Index key } \\
\text { structures } \\
\qquad\left(\mu_{, j}\right)\end{array}$ & $\begin{array}{c}\text { Ambulatory } \\
\text { healthcare } \\
\text { services } \\
\text { (commodity 54) }\end{array}$ & $\begin{array}{l}\text { Hospitals and } \\
\text { nursing and } \\
\text { residential } \\
\text { (commodity 55) }\end{array}$ \\
\hline$\mu_{., 1}$ & 0.05 & 0.07 & $\mu_{., 35}$ & 1.24 & 0.47 \\
\hline$\mu_{., 2}$ & 0.49 & 0.58 & $\mu_{., 36}$ & 14.33 & 2.65 \\
\hline$\mu_{., 3}$ & 0.29 & 0.32 & $\mu_{., 37}$ & 4.23 & 0.65 \\
\hline$\mu_{., 4}$ & 0.97 & 0.62 & $\mu_{., 38}$ & 6.18 & 0.67 \\
\hline$\mu_{., 5}$ & 1.10 & 0.81 & $\mu_{., 39}$ & 2.67 & 1.63 \\
\hline$\mu_{., 6}$ & 0.08 & 0.41 & $\mu_{., 40}$ & 2.17 & 2.12 \\
\hline$\mu_{., 7}$ & 0.27 & 0.66 & $\mu_{., 41}$ & 5.72 & 3.72 \\
\hline$\mu_{., 8}$ & 2.78 & 1.92 & $\mu_{., 42}$ & 1.42 & 3.98 \\
\hline$\mu_{., 9}$ & 0.00 & 0.18 & $\mu_{., 43}$ & 4.67 & 5.65 \\
\hline$\mu_{., 10}$ & 0.80 & 0.65 & $\mu_{., 44}$ & 8.47 & 11.82 \\
\hline$\mu_{., 11}$ & 1.35 & 1.17 & $\mu_{., 45}$ & 1.91 & 8.94 \\
\hline$\mu_{., 12}$ & 0.14 & 0.33 & $\mu_{., 46}$ & 3.11 & 1.46 \\
\hline$\mu_{., 13}$ & 1.64 & 2.54 & $\mu_{., 47}$ & 0.15 & 8.70 \\
\hline$\mu_{., 14}$ & 0.27 & 0.62 & $\mu_{., 48}$ & 4.76 & 9.97 \\
\hline$\mu_{., 15}$ & 1.81 & 1.89 & $\mu_{., 49}$ & 0.78 & 2.07 \\
\hline$\mu_{., 16}$ & 1.03 & 1.56 & $\mu_{., 50}$ & 0.64 & 2.88 \\
\hline$\mu_{., 17}$ & 3.21 & 3.32 & $\mu_{., 51}$ & 2.67 & 3.96 \\
\hline$\mu_{., 18}$ & 0.22 & 0.98 & $\mu_{., 52}$ & 1.88 & 1.58 \\
\hline$\mu_{., 19}$ & 0.60 & 1.16 & $\mu_{., 53}$ & 0.42 & 1.99 \\
\hline$\mu_{,, 20}$ & 1.42 & 0.58 & $\mu_{., 54}$ & 0.29 & 4.99 \\
\hline$\mu_{., 21}$ & 1.23 & 1.82 & $\mu_{., 55}$ & 1.42 & 2.01 \\
\hline$\mu_{., 22}$ & 1.19 & 1.12 & $\mu_{., 56}$ & 3.76 & 3.54 \\
\hline$\mu_{., 23}$ & 5.52 & 3.92 & $\mu_{., 57}$ & 2.00 & 7.07 \\
\hline$\mu_{., 24}$ & 0.17 & 1.13 & $\mu_{., 58}$ & 1.38 & 1.80 \\
\hline$\mu_{., 25}$ & 1.02 & 0.28 & $\mu_{., 59}$ & 1.86 & 2.02 \\
\hline$\mu_{., 26}$ & 0.09 & 1.22 & $\mu_{., 60}$ & 1.19 & 3.87 \\
\hline$\mu_{., 27}$ & 5.66 & 1.87 & $\mu_{., 61}$ & 0.28 & 2.95 \\
\hline$\mu_{., 28}$ & 0.34 & 0.13 & $\mu_{,, 62}$ & 0.71 & 0.28 \\
\hline$\mu_{., 29}$ & 2.60 & 0.30 & $\mu_{., 63}$ & 0.10 & 5.57 \\
\hline
\end{tabular}


Healthcare expenditure and income generation

Table 2 The value index of key policy for the objective variable: $\mu_{54, j}$ (ambulatory healthcare services) and $\mu_{55, j}$ (hospitals and nursing and residential care facilities) (continued)

\begin{tabular}{lccccc}
\hline $\begin{array}{l}\text { Index key } \\
\text { structures } \\
\left(\mu_{., j}\right)\end{array}$ & $\begin{array}{c}\text { Ambulatory } \\
\text { healthcare } \\
\text { services } \\
\text { (commodity 54) }\end{array}$ & $\begin{array}{c}\text { Hospitals and } \\
\text { nursing and } \\
\text { residential } \\
\text { (commodity 55) }\end{array}$ & $\begin{array}{c}\text { Index key } \\
\text { structures } \\
\left(\mu_{., j}\right)\end{array}$ & $\begin{array}{c}\text { Ambulatory } \\
\text { healthcare } \\
\text { services } \\
\text { (commodity 54) }\end{array}$ & $\begin{array}{c}\text { Hospitals and } \\
\text { nursing and } \\
\text { residential } \\
\text { (commodity 55) }\end{array}$ \\
\hline$\mu_{., 30}$ & 0.81 & 3.43 & $\mu_{., 64}$ & 2.42 & 4.77 \\
$\mu_{., 31}$ & 2.42 & 0.28 & $\mu_{., 65}$ & 0.09 & 1.10 \\
$\mu_{., 32}$ & 0.80 & 0.80 & $\mu_{., 66}$ & 0.30 & 0.69 \\
$\mu_{., 33}$ & 6.03 & 1.20 & $\mu_{., 67}$ & 1.27 & 1.06 \\
$\mu_{., 34}$ & 3.01 & 0.18 & & & \\
\hline
\end{tabular}

We can see that commodity ambulatory healthcare services expresses an important influence into 40 key objective structures among $67\left(\mu_{54, j}>1\right)$. Table 2 shows that the good Ambulatory healthcare services demonstrates the most relevance in structure 36.

Into detail, the key-objective-structure 36, whose composition is showed in Figure 4, manifests an important change of this type of private health output. The structure also enhances the good furniture and related products (17), truck transportation (32) and miscellaneous manufacturing (18).

As above, we can see that the good hospitals and nursing and residential care facilities (55) has an important position into structure 43 among $67\left(\mu_{55, j}>1\right)$. From Table 2 it can be stressed the key-objective-structures 44 .

Figure 4 Ambulatory healthcare services - key-objective-structure36 (see online version for colours)

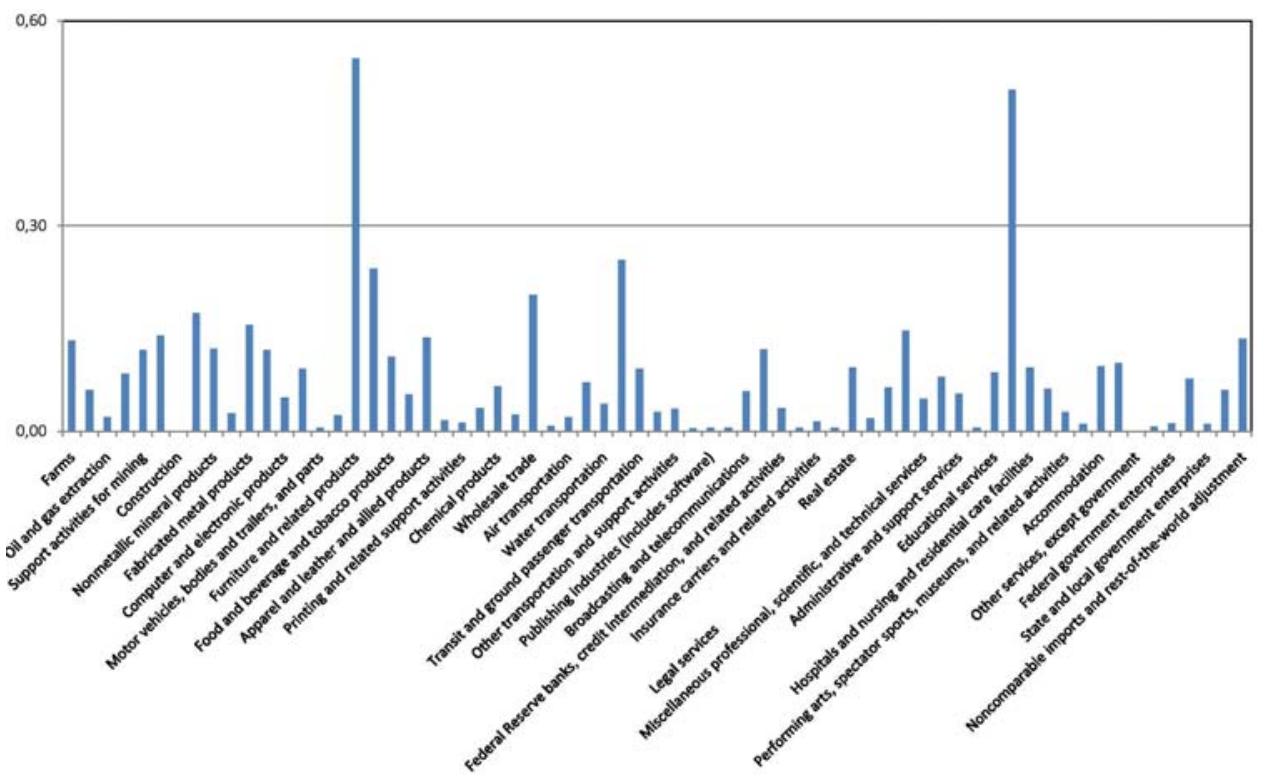


Figure 5 The index of key policy for the objective variable (hospitals and nursing and residential care facilities) (see online version for colours)

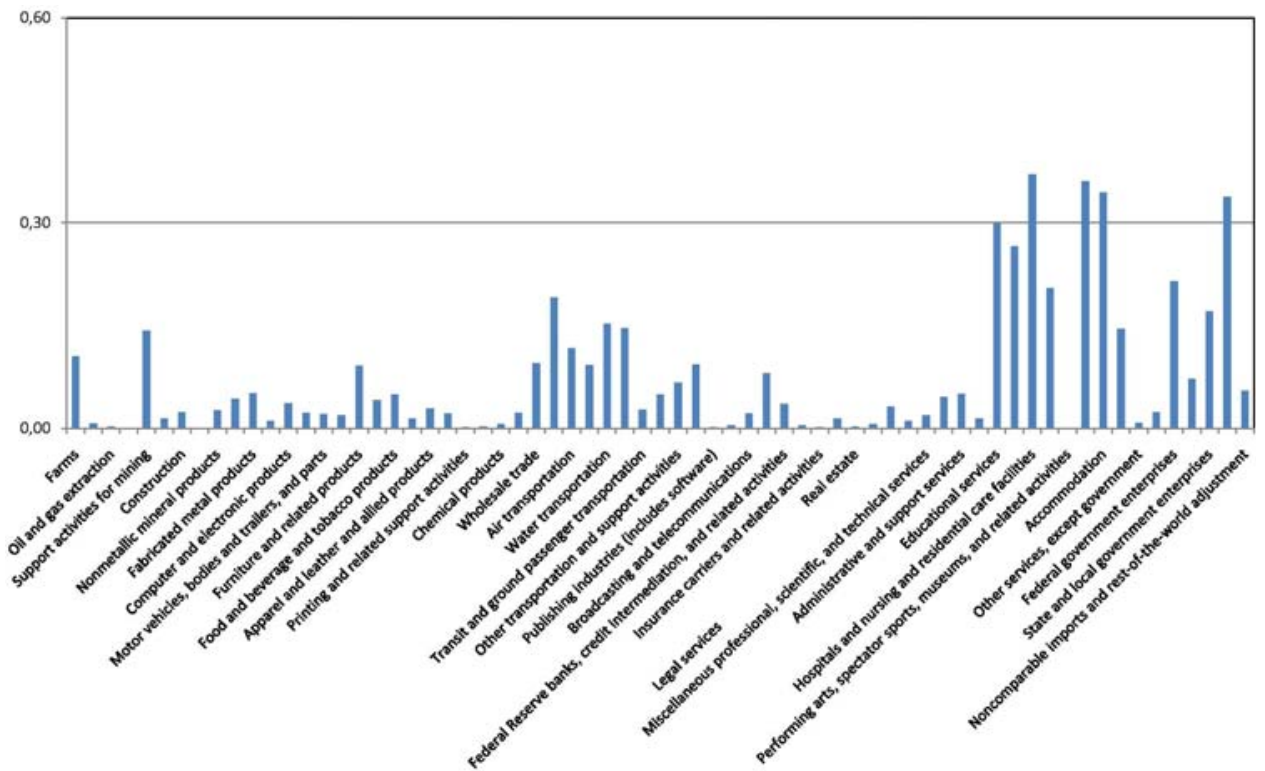

The composition of structure 44 besides enhancing output hospitals and nursing and residential care facilities shows the high importance of all healthcommodity ${ }^{12}$.

The key structures for the commodity hospitals and nursing and residential care facilities also closely involve other commodities such as amusements, gambling and recreation (58), accommodation industries (59), scrap, used and second hand goods (66) and educational services (53). Interdependences between the components of the target vector derive from inter-industry interdependences between healthcare and the highlighted commodities and from the effects on final demand of the generation, distribution and redistribution of income.

\subsection{The key control structures index}

According to equation (3) it is possible to calculate the index of the key control structures for the commodities ambulatory healthcare services and hospitals and nursing and residential care facilities. Then we check the contribution of healthcare goods in income generation.

The indexes allow identifying the key structures of final demand in which the health commodity plays a significant role. In this respect, the key-control-structures index has the potential to reveal which type of good is favoured by the key policies choose according the value of the index.

We can see that the commodity Ambulatory healthcare services (commodity 54) gets an important role into 22 key-control-structures $-\gamma_{54, j}>1-$ among all 67 structures. Table 3 shows the value of the index $\gamma_{i j}$. 
Healthcare expenditure and income generation

Table 3 The index of key policy for the control variable $\left(\gamma_{54 j}\right)($ ambulatory healthcare services) and $\left(\gamma_{55 j}\right)$ (hospitals and nursing and residential care facilities)

\begin{tabular}{|c|c|c|c|c|c|}
\hline $\begin{array}{l}\text { Index key } \\
\text { structures } \\
\left(\gamma_{., j}\right)\end{array}$ & $\begin{array}{c}\text { Ambulatory } \\
\text { healthcare } \\
\text { services } \\
\text { (commodity 54) }\end{array}$ & $\begin{array}{l}\text { Hospitals and } \\
\text { nursing and } \\
\text { residential } \\
\text { (commodity 55) }\end{array}$ & $\begin{array}{c}\text { Index key } \\
\text { structures } \\
\left(\gamma_{., j}\right)\end{array}$ & $\begin{array}{c}\text { Ambulatory } \\
\text { healthcare } \\
\text { services } \\
\text { (commodity 54) }\end{array}$ & $\begin{array}{l}\text { Hospitals and } \\
\text { nursing and } \\
\text { residential } \\
\text { (commodity 55) }\end{array}$ \\
\hline$\gamma_{., 1}$ & 0.64 & 0.69 & $\gamma_{., 35}$ & 0.47 & 0.31 \\
\hline$\gamma_{,, 2}$ & 0.49 & 0.61 & $\gamma_{., 36}$ & 6.37 & 1.18 \\
\hline$\gamma_{, 3}$ & 0.03 & 0.04 & $\gamma_{,, 37}$ & 1.91 & 0.36 \\
\hline$\gamma_{., 4}$ & 0.80 & 0.52 & $\gamma_{., 38}$ & 2.87 & 0.34 \\
\hline$\gamma_{., 5}$ & 0.66 & 0.41 & $\gamma_{., 39}$ & 1.27 & 0.72 \\
\hline$\gamma_{., 6}$ & 0.02 & 0.38 & $\gamma_{., 40}$ & 0.91 & 1.04 \\
\hline$\gamma_{, 7}$ & 0.01 & 0.25 & $\gamma_{., 41}$ & 2.53 & 1.67 \\
\hline$\gamma_{., 8}$ & 1.56 & 1.02 & $\gamma_{., 42}$ & 0.61 & 1.80 \\
\hline$\gamma_{., 9}$ & 0.31 & 0.22 & $\gamma_{., 43}$ & 2.16 & 2.45 \\
\hline$\gamma_{., 10}$ & 0.44 & 0.34 & $\gamma_{., 44}$ & 3.77 & 5.19 \\
\hline$\gamma_{., 11}$ & 0.80 & 0.71 & $\gamma_{., 45}$ & 0.88 & 4.05 \\
\hline$\gamma_{, 12}$ & 0.26 & 0.43 & $\gamma_{., 46}$ & 1.37 & 0.69 \\
\hline$\gamma_{., 13}$ & 0.80 & 1.35 & $\gamma_{, 47}$ & 0.08 & 4.28 \\
\hline$\gamma_{., 14}$ & 0.29 & 0.52 & $\gamma_{., 48}$ & 2.14 & 4.22 \\
\hline$\gamma_{., 15}$ & 1.02 & 1.12 & $\gamma_{., 49}$ & 0.34 & 0.91 \\
\hline$\gamma_{., 16}$ & 0.44 & 0.68 & $\gamma_{., 50}$ & 0.25 & 1.25 \\
\hline$\gamma_{., 17}$ & 1.60 & 1.70 & $\gamma_{., 51}$ & 1.16 & 1.75 \\
\hline$\gamma_{., 18}$ & 0.19 & 0.64 & $\gamma_{., 52}$ & 0.82 & 0.68 \\
\hline$\gamma_{., 19}$ & 0.15 & 0.47 & $\gamma_{., 53}$ & 0.22 & 0.92 \\
\hline$\gamma_{., 20}$ & 0.50 & 0.10 & $\gamma_{,, 54}$ & 0.20 & 2.11 \\
\hline$\gamma_{, 21}$ & 0.47 & 0.80 & $\gamma_{., 55}$ & 0.55 & 0.82 \\
\hline$\gamma_{., 22}$ & 0.52 & 0.51 & $\gamma_{., 56}$ & 1.58 & 1.55 \\
\hline$\gamma_{, 23}$ & 2.55 & 1.79 & $\gamma_{., 57}$ & 0.95 & 3.12 \\
\hline$\gamma_{., 24}$ & 0.18 & 0.69 & $\gamma_{., 58}$ & 0.73 & 0.86 \\
\hline$\gamma_{., 25}$ & 0.52 & 0.16 & $\gamma_{., 59}$ & 0.82 & 0.72 \\
\hline$\gamma_{., 26}$ & 0.06 & 0.61 & $\gamma_{., 60}$ & 0.54 & 1.69 \\
\hline$\gamma_{., 27}$ & 2.69 & 0.90 & $\gamma_{., 61}$ & 0.15 & 1.15 \\
\hline$\gamma_{., 28}$ & 0.02 & 0.10 & $\gamma_{., 62}$ & 0.33 & 0.19 \\
\hline$\gamma_{, 29}$ & 1.16 & 0.20 & $\gamma_{., 63}$ & 0.02 & 2.26 \\
\hline$\gamma_{., 30}$ & 0.34 & 1.65 & $\gamma_{., 64}$ & 0.50 & 1.27 \\
\hline$\gamma_{., 31}$ & 1.08 & 0.18 & $\gamma_{, .65}$ & 1.05 & 0.82 \\
\hline$\gamma_{, 32}$ & 0.42 & 0.45 & $\gamma_{., 66}$ & 1.18 & 1.21 \\
\hline$\gamma_{., 33}$ & 2.79 & 1.56 & $\gamma_{., 67}$ & 0.35 & 0.36 \\
\hline$\gamma_{, 34}$ & 1.42 & 0.12 & & & \\
\hline
\end{tabular}


Between the key control structures, the structure 36, whose composition is showed in Figure 4, is the more interesting. In order to activate this structure it is also necessary to enhance other commodities with the healthcare services: for example, furniture and related products (17), truck transportation (32), wholesale trade (27) and miscellaneous manufacturing (18).

We can see that good hospitals and nursing and residential care facilities (55) gets an important role into 25 key-control-structures $-\gamma_{55, j}>1$ - among 67 (see Table 3). Structure 44 is the more interesting among the 25 key-control-structures (its composition is showed in Figure 7).

In activating this key policy, the goods Amusements, gambling and recreation (58), accommodation industries (59), scrap, used and second hand goods (66), educational services (53), social assistance (56), federal government (62) and state and local government (64) are important to activate the structure.

The structure of the final demand in which healthcare services have the role of policy instruments, cannot be apart from the interaction of all vector components. In other words, healthcare services have to 'move' together with the other final demand components to be used as an economic policy instrument.

The intensity of the connection is rigid and it derives from a structure endogenously predetermined by the model. In the case of healthcare services, as previously shown in Figures 6 and 7, the final demand structures, in which the role of healthcare goods in terms of economic policy instrument is relevant, show a marked difference between the hospital and ambulatory services. In the case of ambulatory healthcare services the use of such commodities as an instrument to achieve predetermined economic policy objectives, is mostly associated to changes in manufactured commodities demand. Differently the use of Hospitals and nursing and residential care facilities is mostly associated to changes in the final demand for services.

Figure 6 Ambulatory healthcare services - key-control-structure 36 (see online version for colours)

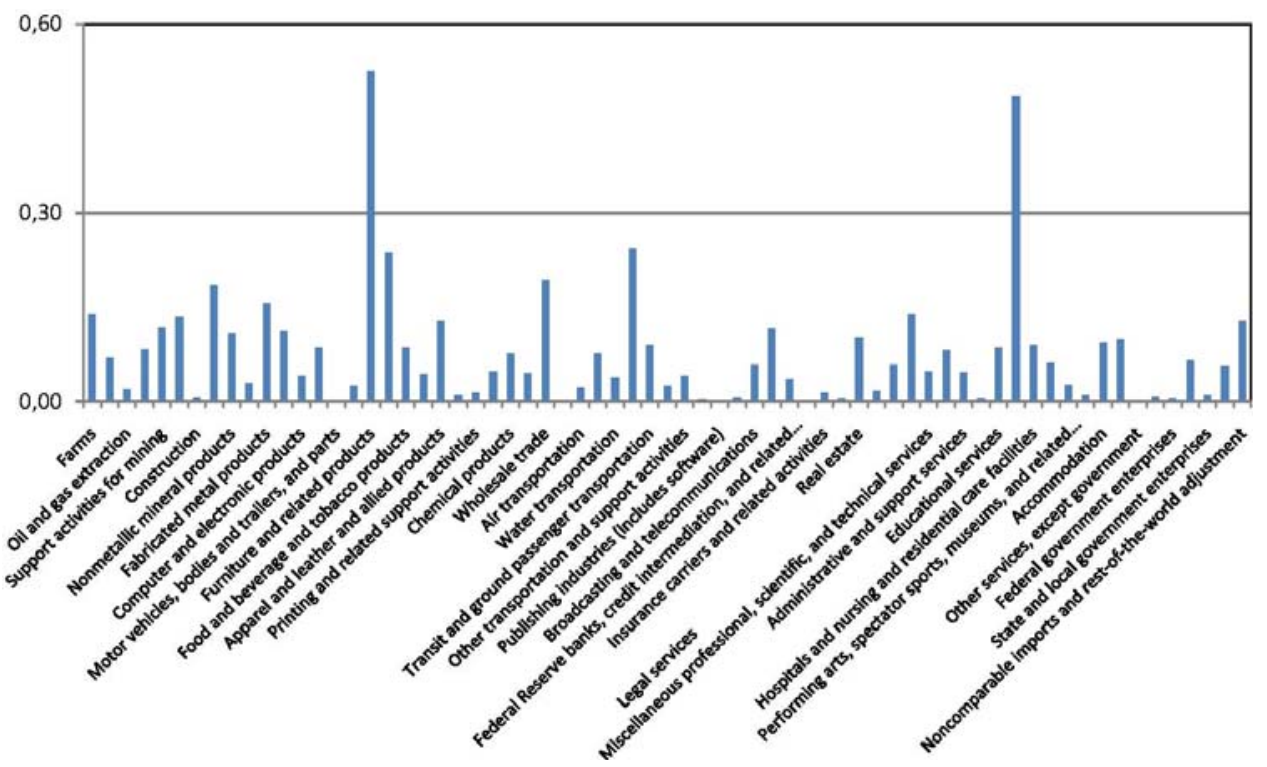


Figure 7 Hospitals and nursing and residential care facilities - key-control-structure 44 (see online version for colours)

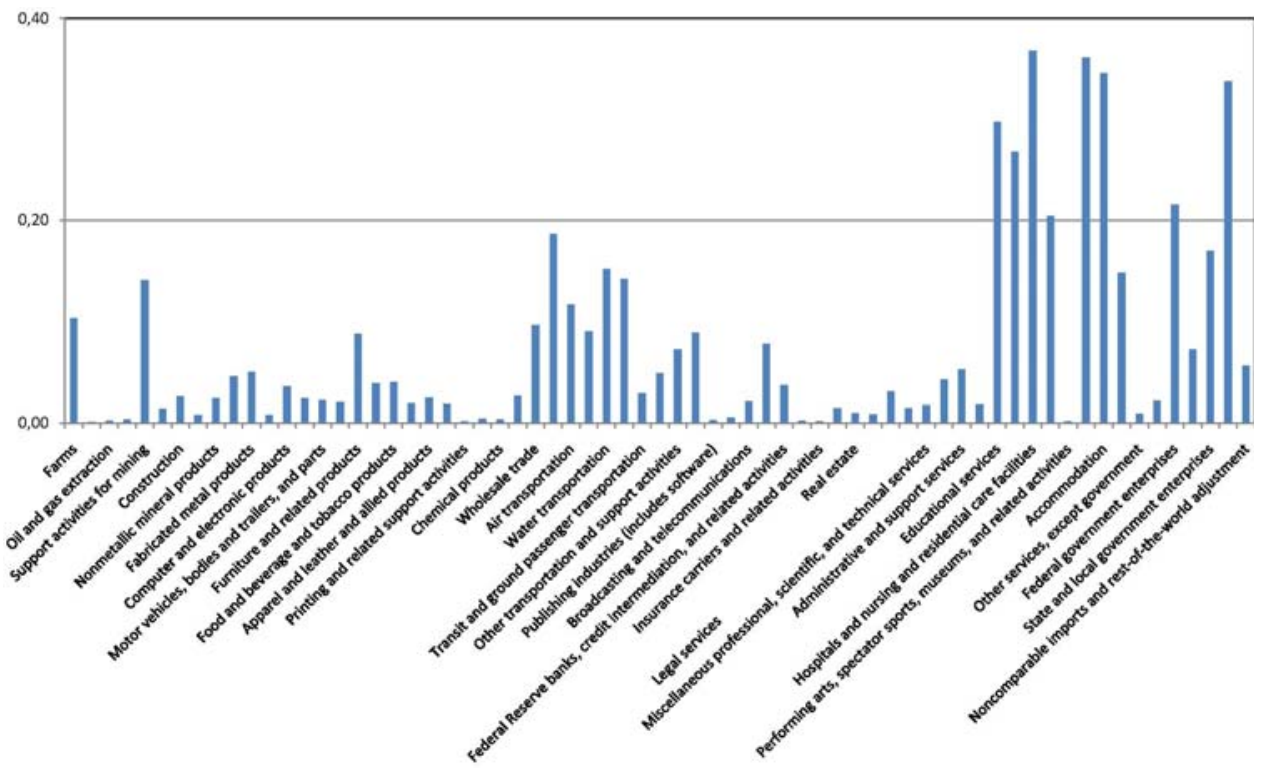

\section{Conclusions}

The production of healthcare services is classified in national accounts in different typologies of services and can be sometimes included in public goods. The political debate focuses on economic and financial sustainability of health systems and their social desirability especially when the central government directly supplies these commodities. As regard the sustainability, the public funding mechanism and the central government supply of healthcare services represents the main concern. Therefore, an attentive analysis of the role played by this sector in the economy in terms of ability to stimulate other production processes, generate income and employment becomes crucial.

Economic policy measures generally aim to stimulate the production and consumption of goods that typically refer to private markets and the policy maker decision are usually sustained by non-economic motives. The analysis of healthcare services production can follow a reversed approach. There are no criticisms on non-economic motivations behind the government decision to finance or directly produce healthcare services. Nevertheless, there are many doubts related to the economic sustainability of this choice. To determine the role of healthcare services production within the income formation is thus a necessary step for policy makers oriented to support these services.

The production of healthcare services is included in the inter-industry relations as well as the other commodities since it is strictly connected with other processes through the absorption of intermediate goods. Its importance derives to its strong ability in activating other production processes (backward look) once its final demand receives a stimulus. Differently it is less important in productive terms when considering its 
contribution to other production processes (forward look). This preliminary analysis allows us to sustain that financing the production of healthcare services is an essential step because it is able to activate the production processes connected to it. However, when the analysis is performed in a general framework that considers the allocation of primary income and the secondary income distribution to determine disposable income, the results could have strong or radical change. Indeed, the role of healthcare services production could change in terms of backward and forward look because of the multiplication processes related to institutional sectors' consumption behaviour and investment propensity.

Once the role of healthcare services within the economic system is determined, it is fundamental to identify what manoeuvre should be used if the objective is encouraging this production processes or stimulating its production because it represents a driver sector for the economy. When the healthcare production is a target, we conduct the analysis from the forward look. Differently, when the healthcare production is functional to other production processes, we conduct the analysis from the backward look.

The results of the analysis reveal that healthcare production plays a key role in US economy. From the backward look, in US the production of ambulatory healthcare services has a minor role compared to hospitals and nursing and residential care facilities. The latter are able to activate other productions, thus they can be considered for any economic policy. On the other hand, from the forward look it is possible to observe that both healthcare productions play the role of key sectors. This is the consequence of the primary and secondary income allocation and final demand formation in other commodities. The incomes generated and allocated by these production processes are significantly destined to final consumption and investment. The so far evidence allows the policy maker to focus in allocating financial resources to increase different healthcare services production or to obtain significant effects on the entire economic system by means of these activities.

To this end, the analysis shows that when the production of healthcare services represents the policy maker objective, it is necessary to allocate economic resources to the final demand that has a certain composition.

In particular, the production of ambulatory healthcare services is stimulated when the policy objective are furniture and related products (17), truck transportation (32) and miscellaneous manufacturing (18). Differently the production of hospitals and nursing and residential care facilities is stimulated when the policy objective favours amusements, gambling and recreation (58), accommodation industries (59), scrap, used and second hand goods (66) and educational services (53).

When the production of healthcare services is the policy control, it is necessary to analyse the economic system and evaluate in which cases these services are endogenously relevant in final demand composition. Given 67 potential final demand structures identified by the system, ambulatory healthcare services and hospitals and nursing and residential care facilities are relevant in the structures 22 and 25 . In the final demand structures where ambulatory healthcare services is relevant there are also other commodities that should be stimulated. They are Furniture and related products (17), truck transportation (32), wholesale trade (27) and miscellaneous manufacturing (18). Differently, in the structures of final demand where Hospitals and nursing and residential care facilities is relevant, the other significant components are amusements, gambling and recreation (58), accommodation industries (59), scrap, used and second 
hand goods (66), educational services (53), social assistance (56), federal government (62) and state and local government (64).

\section{References}

Al-Ississ, M.M. and Miller, N.H. (2013) 'What does health reform mean for the health care industry? Evidence from the Massachusetts special senate election', Journal Economic Policy, Vol. 5, No. 3, pp.1-29.

BEA (2009) Annual Input-Output Data, US Bureau of Economic Analysis [online] http://www.bea.gov.

Bulmer-Thomas, V. (1982) Input-Output Analysis in Developing Countries, John Wiley and Sons Ltd, USA.

Busse, R. (2002) 'Expenditure on health care in the EU: making projections for the future based on the past', HEPAC: Health Economics in Prevention and Care, Vol. 2, No. 4, pp.158-161.

Ciaschini, M. and Socci, C. (2007a) 'Final demand impact on output: a macro multiplier approach', Journal of Policy Modeling, Vol. 29, No. 1, pp.115-132.

Ciaschini, M. and Socci, C. (2007b) 'Bi-regional SAM linkages: a modified backward and forward dispersion approach', Reviews of Urban and Regional Development Studies, Vol. 19, No. 3, pp.233-254.

Ciaschini, M., Pretaroli, R. and Socci, C. (2009) 'A convenient multi sectoral policy control for the ICT in the U.S.A. economy', Metroeconomica, Vol. 60, No. 4, pp.660-685.

Ciaschini, M., Pretaroli, R. and Socci, C. (2010) 'Health-care in Europe as a driving force for output and GDP', in Prinz, A., Steenge, B., Hospers, G.J. and Lamgem, M. (Eds.): Global Forces, Local Identity: The Economics of Cultural Diversity, Chap. 3, pp.106-135, Lit Verlag, Germany.

Ciaschini, M., Pretaroli, R. and Socci, C. (2011) 'A convenient multi sectoral policy control for the ICT in the U.S.A. economy', Structural Change and Economics Dynamic, Vol. 22, No. 3, pp.204-226, doi:10.1016/j.strueco.2011.03.002.

Fogel, R.W. (2009) 'Forecasting the cost of U.S. health care in 2040', Journal of Policy Modeling, Vol. 31, No. 4, pp.482-488.

Hall, R.E. and Jones, C.I. (2007) 'The value of life and the rise in health spending', Quarterly Journal of Economics, Vol. 122, No. 1, pp.39-72.

Lancaster, P. and Tiesmenetsky, M. (1985) The Theory of Matrices, 2nd ed., Academic Press, New York.

Leontief, W., Morgan, A., Polenske, K., Simpson, D. and Tower, E. (1965) 'The economic impact - industrial and regional - of the arms cut', Review of Economics and Statistics, Vol. 47, No. 3, pp.217-241.

Miller, R.E. and Blair, P.D. (2010) Input-Output Analysis: Foundations and Extensions, 2nd ed., Prentice-Hall, Inc., Englewood Cliffs, New Jersey.

Miyazawa, K. (1976) 'Input-output analysis and structure of income distribution', Notes in Economics and Mathematical Systems, Vol. 116, New York.

Rasmussen, P. (1956) Studies in Intersectoral Relations, North Holland Publishing Company, Amsterdam

Skolka, J. (1986) 'Input-output multipliers and linkages', Paper presented at 8th International Conference on Input-Output Techniques, Sapporo.

United Nations (UN) (1993) System of National Accounts, N.U., New York. 


\section{Notes}

1 The health spending rose from $5.2 \%$ in 1960 to $16.2 \%$ in 2008 . The expectation is for an increase of the share to more than $19 \%$ by 2019 (BEA, 2009).

2 "Just as electricity and manufacturing were the industries that stimulated the growth of the rest of the economy at the beginning of the 20th century, healthcare is the growth industry of the 21st century" (Fogel, 2009).

3 The multi-sectoral analysis is an appropriate tool able to analyse the articulated description of the income/value added generation process which, starting from the final demand of goods and services, takes account of the contribution of each producing sector to the income formation (Leontief, 1965).

4 Although the traditional tools of multi-sectoral analysis can reveal the relevance of a commodity in the production process it cannot face the problem concerning the composition of the shock to be conveyed as policy control on final demand (Skolka, 1986).

5 The flows are expressed in million of dollars.

6 The households, business, federal government, state and local government and rest of the world.

7 Its aggregate numerical determination is shown in Table 1.

8 The mathematical aspects are presented in Appendix.

9 The universality of the healthcare system coverage is a principle that leads to a strong pressure on the public budget.

10 Many counties in US today base their production mainly on market oriented healthcare services. The creation of health districts is now a prerogative.

11 When the index is smaller than 1 then the good has a low importance inside both the key objectives and control structures.

12 The composition of the structure is showed in Figure 5.

\section{Appendix A}

\section{Details on extended multi-sectoral model}

The extended multi-sectoral model starts from following the fundamental equation:

$$
x+i m=B i+f
$$

where $x$ is the output vector by industry, im is imports vector, $B$ is intermediates consumption and $f$ is final demand vector. Our extended I-O model has a great part of final demand endogenous. For this reason, we determine the distributive structural matrices for endogenous final demand analysis.

- Gross value added generation (by I-O sectors)

$$
v(x)=L x
$$

where $L[n, n]$ gives the shares of value added by industry starting from the output vector and technical coefficients matrix. 
- Gross value added allocation (by VA components)

$$
v^{c}(x)=V v
$$

where $V[c, n]$ represents the distribution of value added to the factors (components).

- $\quad$ Primary distribution of income (by institutional sectors)

$$
v^{s}(x)=P v^{c}
$$

where $P[s, c]$ represents the distribution factors' value added income to the sectors.

- Secondary distribution of income (by institutional sectors)

$$
y(x)=(I+T) v^{s}
$$

where $T[s, s]$ represents net income transfers among sectors and $I$ is the identity matrix $[s, s]$.

- $\quad$ Final demand formation (by I-O sectors)

$$
x=F^{0} y+K y+f^{0}
$$

where $F^{0}$ provide the consumption demand structure by industry and is given by the product of two matrices, $F^{0}=F^{1} C$, where $F^{1}[n, s]$ transforms the consumption expenditure by institutional sector into consumption by industry and $C[s, s]$ represents the consumption propensity by institutional sector. The matrix $K$ represents the investment demand shares and is given by $K=K^{1} i(I-C)$ where $K^{1}[n, s]$ represents the investment demands to I-O industry and scalar $i$ represents the share of private savings which is transformed into investment i.e., 'active savings'; $f^{\theta}$ is a vector of $\mathrm{m}$ elements which represents exogenous demand (exports).

If we put $F=F^{0}+K$ equation (A6) becomes

$$
f-F y+f^{0}
$$

Substituting the equations (A1)-(A6) in (A7) we get

$$
x=F[I+T] P V L x+f^{0}
$$

We now turn to the output generation process shown in equation (A1).

- Output generation

$$
x+i m=A x+f
$$

where $A$ is the technical coefficients matrix. Substituting the equations (A8) in equation (A9) we finally get:

$$
x=[I-A-F(I+T) P V L]^{-1}\left(f^{0}-m\right)
$$

We can define the structural matrix of the reduced form of the model as follows:

$$
R=[I-A-F(I+T) P V L]^{-1}
$$




\section{Appendix B}

\section{Singular value decomposition or MM approach}

The decomposition proposed can be applied both to square and to non-square matrices. Here the general case of square matrix $R$ will be shown. The non-square matrix case is easily developed along the same lines.

To simplify we consider $2 \times 2$ model. Let us consider matrix W [2, 2], for example, the square of matrix R:

$$
W=R^{T} R=
$$

Matrix $W$ has a positive definite or semi definite square root. Given that $W \geq 0$ by construction, its eigenvalues $\lambda_{i}$ for $i=1,2$ shall be all real non-negative.

The non-zero eigenvalues of matrices $W$ and $W^{T}$ coincide. The system of eigenvectors $\left[u_{i}, i=1,2\right]$ for $W$ and $\left[p_{i}, i=1,2\right]$ for $W^{T}$ are orthonormal basis.

We get then

$$
R^{T} z_{i}=\sqrt{\lambda_{i}} p_{i} \quad i=1,2
$$

We can construct the two matrices

$$
Z=\left[z_{1}, z_{2}\right] \quad P=\left[p_{1}, p_{2}\right]
$$

As defined above, the eigenvalues of $W$ coincide with singular values of $R$ hence $s_{i}=\sqrt{\lambda_{i}}$ and we get

$$
R^{T} Z=\left[s_{1} p_{1}, s_{2} p_{2}\right]=P M
$$

Structural matrix $R$ in equation (A11) can be then decomposed as

$$
x=Z M P^{T} f
$$

$P$ is a $[2,2]$ unitary matrix whose columns define the two reference structures for final demand:

$$
\begin{aligned}
& p_{1}=\left[p_{11}, p_{12}\right] \\
& p_{2}=\left[p_{21}, p_{22}\right]
\end{aligned}
$$

$Z$ is a $[2,2]$ unitary matrix whose columns define the 2 reference structures for output:

$$
z_{1}=\left[\begin{array}{l}
z_{11} \\
z_{21}
\end{array}\right], \quad z_{2}\left[\begin{array}{l}
z_{12} \\
z_{22}
\end{array}\right]
$$

and $M$ is a [2,2] diagonal matrix of the type:

$$
M=\left[\begin{array}{ll}
m_{1} & 0 \\
0 & m_{2}
\end{array}\right]
$$


Scalars $m_{i}$ are all real and positive and can be ordered as $m_{1}>m_{2}$. Now we have all the elements to show how this decomposition correctly represents the MM that quantify the aggregate scale effects and the associated structures of the impact of a shock in disposable income on total output. In fact if we express the actual vector $f$ in terms of the structures identified by matrix $P$, we obtain final demand vector, $f^{\circ}$, expressed in terms of the structures suggested by the $R$ :

$$
f^{0}=P f
$$

On the other hand we can also express total output according the output structures implied by matrix $R$ :

$$
x^{0}=Z^{T} x
$$

Equation (B1) then becomes through equations (B2) and (B3):

$$
x^{0}=M f^{0}
$$

which implies:

$$
x_{i}^{0}=m_{i} f_{i}^{0}
$$

where $i=1,2$. We note that matrix $R$ hides two fundamental combination of the outputs. Each of them is obtained multiplying the corresponding combination of final demand by a predetermined scalar, which has in fact the role of aggregated MM.

The complex effect of final demand shocks on the output vector can be reduced to a multiplication by a constant $m_{i}$.

The structures we have identified play a fundamental role in determining the potential behaviour of the economic system, i.e., the behaviour of the system under all possible shocks. We can in fact evaluate which will be the effect on output of all final demand possible structures. This is easy by imposing in equation (B1) a vector whose modulus is constant, say equal to one, but whose structure can assume all possible configurations. If vector $f$ in equation $(\mathrm{B} 1)$ is such that

$$
\sqrt{\sum_{j} f_{j}}=1
$$

then geometrically we mean that the final demand vector describes a sphere of unit radius (the unit circle).

It rotates around the origin assuming all the possible structures, including those implied by the columns of matrix $P$. Correspondingly the vector of total output will describe an ellipsoid with semi-axes of length $m_{1}, \ldots, m_{n}$, oriented according the directions designated by the columns of matrix $Z$. This ellipsoid is sometimes called the isocost of final demand control.

When final demand vector crosses a structure in $P$, the vector of total output crosses the corresponding structure in $Z$ and the ratio between the moduli of the two vectors is given by the corresponding scalar $m$. Singular values $m_{i}$, then, determine the aggregated effect of a final demand shock on output. For this reason, we will call them MMs. These MM are aggregated, in the sense that each of them applies on all components of each macroeconomic variables taken into consideration and are consistent with the multi-industry specification of the model. 
In our original $[n, n]$ extended model, we can than say that, given our matrix $R$, we are able to isolate impacts of different (aggregate) magnitude, since that MM present in matrix $R, m_{i}$ can be activated through a shock along the demand structure $p_{i}$ and its impact can be observed along the output structure $z_{i}$.

\section{Appendix C}

\section{Tables and figures}

Table C1 I-O commodities, primary factors, institutional sectors and capital formation classification

\begin{tabular}{|c|c|}
\hline 1 & Farms \\
\hline 2 & Forestry, fishing, and related activities \\
\hline 3 & Oil and gas extraction \\
\hline 4 & Mining, except oil and gas \\
\hline 5 & Support activities for mining \\
\hline 6 & Utilities \\
\hline 7 & Construction \\
\hline 8 & Wood products \\
\hline 9 & Non-metallic mineral products \\
\hline 10 & Primary metals \\
\hline 11 & Fabricated metal products \\
\hline 12 & Machinery \\
\hline 13 & Computer and electronic products \\
\hline 14 & Electrical equipment, appliances, and components \\
\hline 15 & Motor vehicles, bodies and trailers, and parts \\
\hline 16 & Other transportation equipment \\
\hline 17 & Furniture and related products \\
\hline 18 & Miscellaneous manufacturing \\
\hline 19 & Food and beverage and tobacco products \\
\hline 20 & Textile mills and textile product mills \\
\hline 21 & Apparel and leather and allied products \\
\hline 22 & Paper products \\
\hline 23 & Printing and related support activities \\
\hline 24 & Petroleum and coal products \\
\hline 25 & Chemical products \\
\hline 26 & Plastics and rubber products \\
\hline 27 & Whole sale trade \\
\hline 28 & Retail trade \\
\hline 29 & Air transportation \\
\hline 30 & Rail transportation \\
\hline
\end{tabular}


Table C1 I-O commodities, primary factors, institutional sectors and capital formation classification (continued)

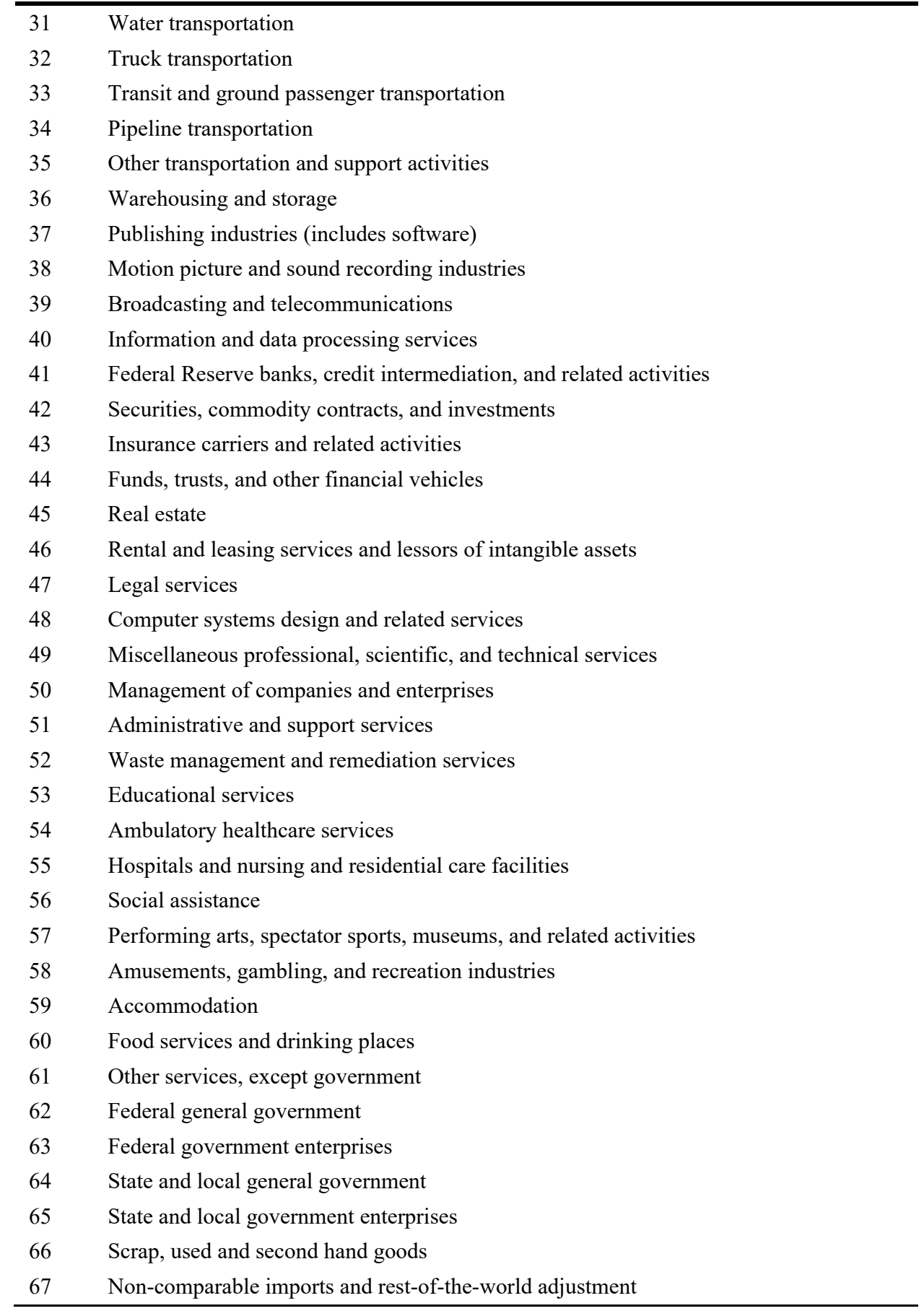


Table C1 I-O commodities, primary factors, institutional sectors and capital formation classification (continued)

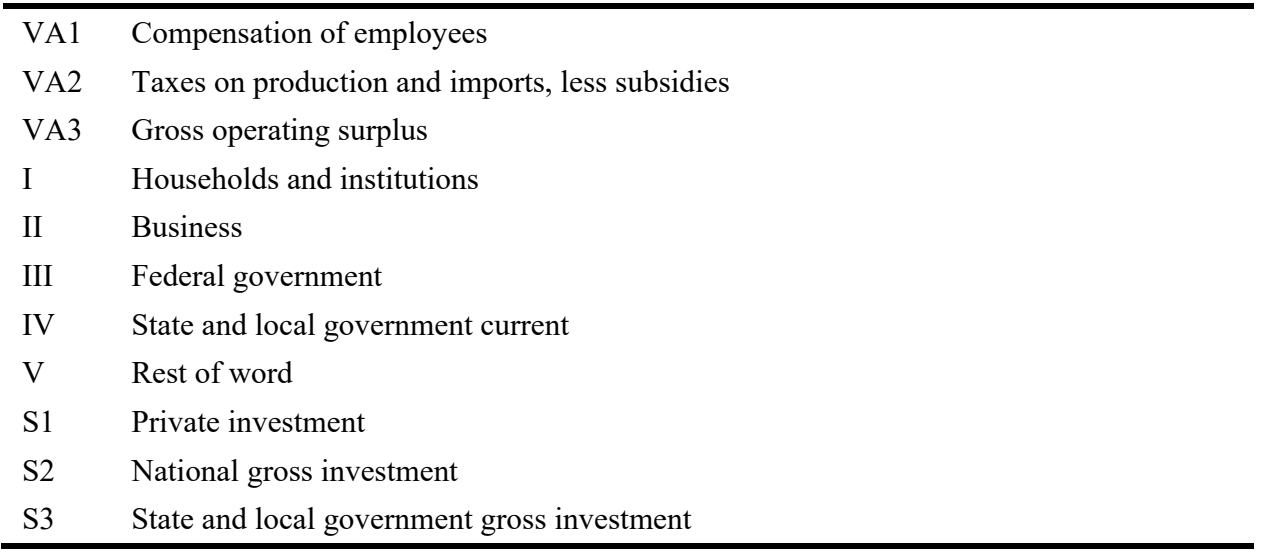

Figure C1 Key-objective-structures

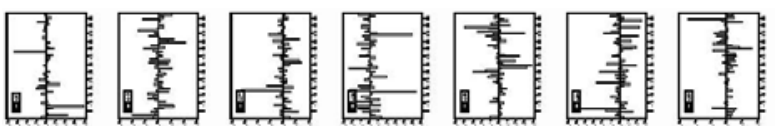

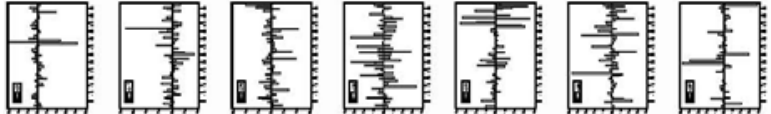

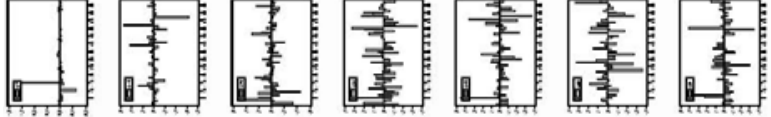

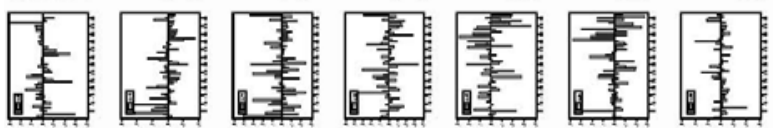

委

支要

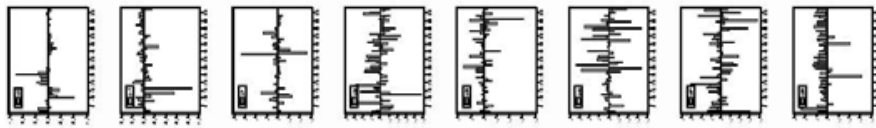

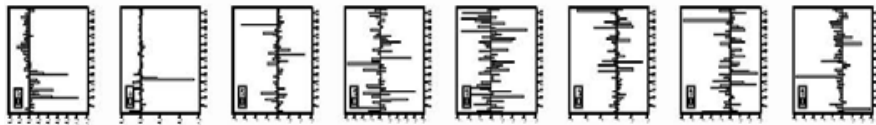

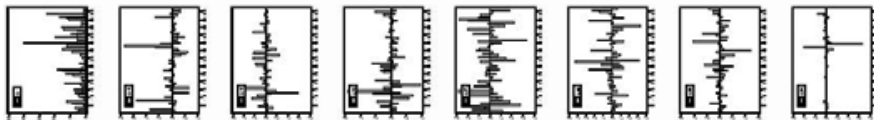


Healthcare expenditure and income generation

Figure C2 Key-control-structures

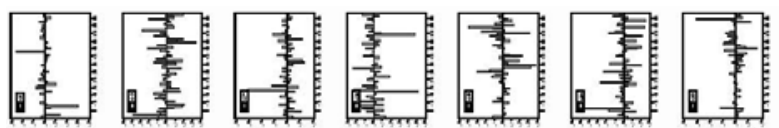

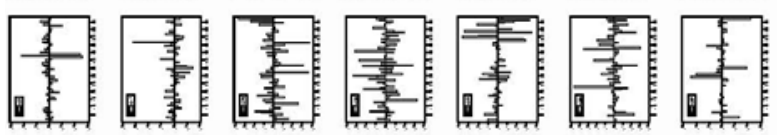

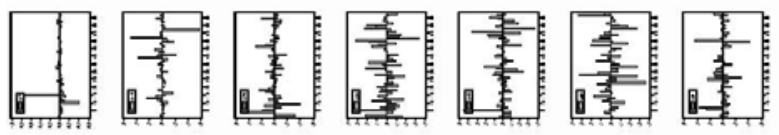

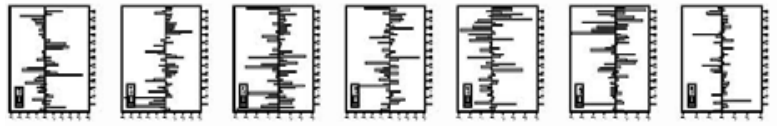

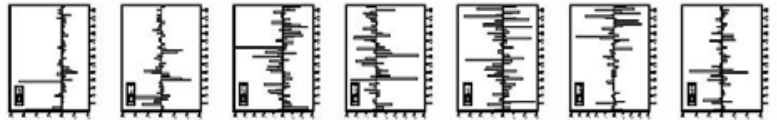

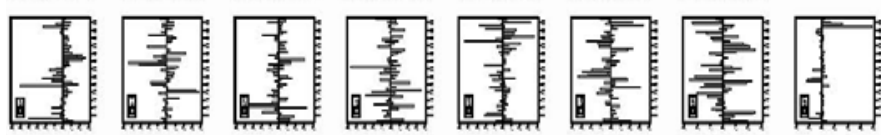

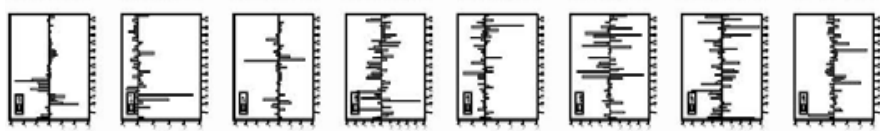

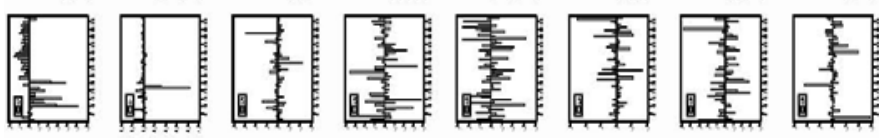

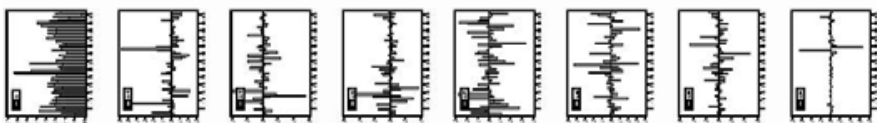

